\title{
DOS DÉCADAS DE ESTUDIOS DE PREHISTORIA DE LA RIOJA
}

\author{
Juan A. Santos Velasco
}

\begin{abstract}
RESUMEN: Con la disculpa de la reedición de la revista de Historia, Brocar, se intenta mostrar un panorama general de lo que han sido los últimos años de la arqueología prehistórica riojana, en la que se ha producido un gran salto cualitativo, pasándose de un conocimiento muy precario de la misma a forjar bases sólidas para su interpretación. En especial en algunos de sus momentos cronológicos y facies culturales más significativas.
\end{abstract}

ABSTRACT: This paper try to be an introductory guide about the last twenty years of prehistorical archaelogical research in La Rioja, where we have surpass a precarious knowledge of it, for putting significants cultural phases.

La reaparición de la revista Brocar se ha convertido en la oportunidad, para el profesorado de la recientemente creada Universidad de La Rioja, para ofrecer una visión general de lo que ha sido la investigación en los últimos años, en cada una de nuestras parcelas de conocimiento. En mi caso concreto sobre la Pre y Protohistoria regionales. Mi reciente incorporación al Departamento de Humanidades de este centro universitario y, en consecuencia, a los problemas que se plantean en la arqueología prehistórica local puede dar origen a algún descuido, no intencionado, que estoy seguro será entendido como tal por todos aquellos profesionales que, de una u otra manera, hayan estado o están comprometidos en la profundización de los estudios de la Prehistoria riojana. Este pequeño trabajo no pretende ser una recopilación exhaustiva, sino un mero guión que sirva, en lo posible, a los lectores como una introducción al tema. 
En una aproximación preliminar al sujeto de este artículo, la primera referencia obligada es la publicación de los Estudios de bibliografía arqueológica riojana: Prehistoria e Historia Antigua, en el año 1981, por U. Espinosa. En su obra se recogen las investigaciones llevadas a cabo en esta Autonomía, hasta fines de los años setenta. En palabras del propio autor, no quiere ser un Repertorio sino un estudio, un instrumento de trabajo para los investigadores.

Pero no es ésta la primera recopilación bibliográfica, elaborada sobre nuestro tema, la cual apareció hace ya más de treinta años y se debe a Vallespí (1960: 207211). Asimismo, habría que contar, en este capítulo, con las Fuentes bibliográficas para la arqueología prerromana (1978) de la profesora $\mathrm{M}^{\mathrm{a}}$.P. Galve, así como con la Recopilación de Arqueología Riojana de la sección de Arqueología del Instituto de Estudios Riojanos (1977).

Un acontecimiento de singular importancia por aquellas fechas fue justamente la creación del Colegio Universitario, en el año 1972, lo que permitió que tomaran asiento aquí un reducido número de prehistoriadores que articularán su trayectoria profesional en torno a esta zona de la península, como son los ejemplos de los profesores Galve y Pérez Arrondo. Esta circunstancia hizo posible que se pusieran las bases de los estudios sobre la Prehistoria del alto y medio Ebro, los cuales irán aumentando progresivamente a lo largo de aquella década. Como cita Espinosa (1981), son los años de la recogida masiva de datos con los que se van a ir dando los primeros pasos en el conocimiento de este período de la Historia del Hombre, en la zona. Los setenta son los años de las excavaciones en Santa Ana (Entrena), Cerro de Sobrán (Calahorra) o El Redal, gracias a las cuales se va a pasar de un prácticamente total desconocimiento de nuestra disciplina a los primeros estudios generales y de síntesis, en especial en ciertas parcelas específicas que, por causas diversas, atrajeron más que otras la atención de los investigadores.

Una de esas parcelas va a ser el Paleolítico, con los estudios de Vallespí (1975), o de Utrilla y Pascual (1981). Asímismo, cabe destacar el análisis de los yacimientos al aire libre, conocidos como talleres de silex, llevado a cabo, asímismo, por Vallespí.

Otros dos focos de interés van a ser, por un lado, el fenómeno megalítico, con las excavaciones de Peña Negra (Nalda) por Pérez Arrondo; y por otro, la II Edad del Hierro, momento para el cual destaca la tesis doctoral de Castiella (1976): La II Edad del Hierro en Navarra y La Rioja, que podemos considerar también la primera síntesis de la Protohistoria regional que, aunque con especial referencia al período cronológico indicado en el título de la obra, plantea también la cuestión de las penetraciones célticas, durante la I Edad del Hierro, a partir de los resultados de las excavaciones del Cerro de Partelapeña (El Redal), de las obras de Arteaga (1977), así como de las de Eiroa (1978). Por estas mismas fechas mencionar, como no, los Trabajos arqueológicos en la Libia de los berones de Marcos Pous (1979).

Los tres temas citados, Paleolítico Inferior y Medio, Megalitismo y Bronce final/Edad del Hierro fueron, en aquellos momentos, los puntales con los que se 
comenzó a trabajar en la región; y aún hoy podemos considerarlos como la vanguardia de la investigación prehistórica riojana. No hay más que darle un repaso a los números de la revista Estrato, publicada por los Servicios de Arqueología de la Comunidad Autónoma, para darse cuenta que aquellos tres ámbitos culturales y cronológicos continúan siendo los que mayor atención atraen.

En líneas generales, se puede decir que durante aquellos años se forjaron los pilares de la Prehistoria como ciencia, en La Rioja, cuya infraestructura se ampliará, con el tiempo, con la creación del Servicio de Patrimonio Histórico Artístico de la Comunidad Autónoma, y la citada revista Estrato, cuyo primer numero sale a la calle en 1989.

Otros hitos de cita imprescindible serán los Congresos de Historia de La Rioja, celebrados en 1982 y 1985 . Reuniones científicas que hay que apreciar en el conjunto de Congresos de Historias nacionales y regionales que se celebran en los años ochenta, en la práctica totalidad del estado, como son los del País Valenciano o el de Castilla-La Mancha. Fenómeno que, a su vez, hay que entender en el contexto político de la España de las Autonomías que nace de la Constitución de 1978. Contexto que nos sirve para encuadrar la publicación de la Historia de La Rioja (1983), dirigida por J. García Prado.

También es obligado mencionar el Congreso sobre el Bimilenario de Calahorra (1984), una nueva ocasión para seguir dando a conocer a la comunidad científica nacional los avances que se van produciendo en la investigación de campo de esta parte del alto y medio Ebro.

Fueron muchas y muy interesantes las aportaciones a los Congresos señalados. Entre ellas podríamos destacar la puesta al día de las antiguas excavaciones de la cueva de Peña Miel, que retoma los antiguos estudios de Lartet (UTRILLA, 1983 y 1986); y El Redal, donde se aclara la secuencia de ocupación de este importante poblado protohistórico (PÉREZ ARRONDO, 1986).

Pero dentro de esta actividad congresual de los ochenta destaca, sin lugar a dudas, la celebración en el entonces Colegio Universitario del XVII Congreso Nacional de Arqueología, en el año 1983, publicado en Zaragoza dos años más tarde y del que, al margen de su interés intrínseco, habría que señalar la oportunidad que brindó para la colaboración, en un objetivo común, entre instituciones de la más diversa índole, pues en su organización intervinieron la Consejería de Educación y Cultura de la Comunidad Autónoma de La Rioja, El Instituto de Estudios Riojanos, el Ayuntamiento de Logroño, la Universidad de Zaragoza y, por supuesto, el Colegio Universitario de La Rioja.

Por lo que se refiere a las aportaciones que se hicieron allí, en el ámbito de nuestra disciplina, hay que hacer notar una continuidad historiográfica y bibliográfica de la trilogía que se apuntó con anterioridad: Paleolítico, Megalitismo y Edad del Hierro.

Destacan los avances en el conocimiento del hombre del Cuaternario y, en especial, los descubrimientos de yacimientos musterienses y del Paleolítico superior en 
La Rioja, Navarra y Aragón, que son objeto de análisis pormenorizados desde e1 punto de vista de la tradición paleolitista francesa, fundamentada en el uso de la tipología analítica. De ello son buen reflejo los trabajos de Utrilla, gracias a los cuales hoy conocemos los yacimientos achelenses de las terrazas III y IV del Najerilla, $\mathbf{y}$ sabemos que el Musteriense local se caracteriza por el alto índice levallois y por tratarse de un Musteriense de tradición Achelense.

Ya a fines de los ochenta y como continuadora de la labor de Utrilla, contamos con el trabajo de Montes El Musteriense de la cuenca del Ebro que, aún prosiguiendo la línea de investigación establecida por Utrilla, incorpora novedades como e1 análisis funcional de Binford y los modelos de Isaac y Foley.

\section{La Prehistoria Reciente}

En cuanto a este período, en todos estos Congresos, se dan a conocer los avances que se van realizado en el estudio de aquel momento pero, por esta misma razón, se hacen más perceptibles las lagunas que van apareciendo. Lagunas sobre fases como el Epipaleolítico, Neolítico o Bronce, que en parte son paliadas gracias a las excavaciones de varios conjuntos dolménicos, en especial en la margen derecha del Ebro, en zonas de comunicación natural entre este valle y la submeseta norte. Fenómeno megalítico cuya datación oscila entre el Neolítico y el Bronce Pleno (PEREZ ARRONDO, 1983: 58), y al que aparecen asociados el vaso campaniforme y los primeros horizontes metalúrgicos, como en el dólmen de Clavijo o el de Agoncillo (GARCIA PRADO, 1983: 73). Tal vez resulte conveniente detenerse en este punto, por un momento. Tradicionalmente se definían dos grupos de monumentos megalíticos, el del oeste de la submeseta norte, en el valle del Duero, y el grupo de la Rioja, del alto Ebro. Este último participaba tanto de influencias del grupo vasco-pirenaico, como del de la cuenca del Duero. Sin embargo, ciertos descubrimientos como El Miradero (Valladolid) apuntan a la definición de un grupo homogéneo en ambos valles, aunque cada uno con caracteres propios. Tesis defendida por Delibes en lo que ha dado en denominar Grupo San Martín-El Miradero. Este investigador insiste en la definición de un único grupo cultural megalítico, en este parte de la península, por las afinidades documentadas entre ambas áreas:

a) El tipo de monumento es siempre el sepulcro de corredor.

b) Aparecen los llamados ídolos-espátula, como principal elemento distintivo del grupo. Idolos de hueso que se hallan en el valle medio del Duero, La Rioja y, entre ellos, actuando como nexo, en La Lora burgalesa.

El tercer centro de atención ha estado y está puesto en las fases finales de los tiempos prehistóricos, sobre los que se ha llevado a cabo una amplia catalogación y ordenación de hallazgos dispersos del Bronce final y la I Edad del Hierro. De estos trabajos surgieron puntos de sumo interés como la presencia de materiales del horizonte Cogotas I, que nos hablan del impacto y penetración de aquel grupo cultural en 
nuestra zona de estudio, si bien parece ser que fue un fenómeno muy localizado, breve y tardío.

Moviéndonos dentro de este ámbito se va a dejar sentir, aunque algo tangencialmente en los estudios de la Prehistoria riojana, el impacto que en todo el estado tuvieron a mediados de los ochenta las nuevas corrientes teóricas y metodológicas anglosajonas, esencialmente la Arqueología espacial, la Arqueología social, y otras.

Inmerso en estos aires de renovación, que pasaron a denominarse genéricamente Nueva Arqueología (introduciéndose un equívoco al identificarse la New Archaeology norteamericana con toda novedad metodológica), contamos con el trabajo de Ruiz Zapatero y Fernández Martínez, presentado al XVII Congreso Nacional de Arqueología, sobre el modelo económico de la I Edad del Hierro en la región. Si bien se trata el caso particular de Cortes de Navarra, localidad no riojana, hay que tener presente que el yacimiento navarro cuenta con los mismos elementos culturales que sus coetáneos riojanos. Razón por la cual he creido necesario mencionarlo.

En la misma línea, se encuentra la tesis doctoral de Ruiz Zapatero sobre Los Campos de Urnas del Noreste de la Península Ibérica (1985), que incluye el alto Ebro, con las áreas del Cidacos y Calahorra, y con El Redal como principal foco de atención. Yacimiento que se paraleliza con el citado lugar de Cortes de Navarra, en donde se vuelve sobre el traído y llevado tema de las migraciones transpirenaicas, reconociendo este autor la entrada de nuevas poblaciones por los pasos occidentales del Pirineo, a fines del Bronce final e inicios de la I Edad del Hierro.

Con todos estos datos, aunque aún escasos, podemos, no obstante, ir perfilando una visión general de la prehistoria final de La Rioja. Sobre un sustrato que cuenta con elementos aislados de Cogotas I (Aguilar del Río Alhama, Alfaro), que sugieren un arraigo pequeño y tardío de aquel horizonte cultural meseteño (HERNANDEZ VERA, 1983), se documenta una facies halstáttica, indoeuropea, según Ruiz Zapatero (1985), cuyas muestras serían, siempre siguiendo a este autor, Cortes de Navarra PIIb y El Redal Ib. Esta fase está caracterizada por la desaparición de las cerámicas acanaladas, excisas e incisas, que retroceden a favor de las formas lisas.

No terminar, en lo que se refiere a los estudios que jalonan el final de la Protohistoria de La Rioja, sin citar el mundo prerromano del Alto Ebro, por la polémica que levanta. Podemos decir, en términos muy generales, que la II Edad del Hierro es el resultado de la iberización del sustrato cultural y étnico que se afianza, como hemos visto, entre el Bronce Final y el Hierro I. Las novedades de origen mediterráneo, expresión de esa iberización, llegan a través del Bajo Aragón y su elemento más característico van a ser las cerámicas a torno, que se documentan a partir de los siglos IV-III a.C. Pero esta fase prerromana es un momento de gran complejidad. Uno de los temas a debate es si en La Rioja estamos en el área cultural estrictamente celtibérica, o no. Geógrafos e historiadores latinos se refieren a lusones, arévacos, belos y titos, como los pueblos celtibéricos, pero no se citan ni a berones, ni a vacceos (VV.AA., 1988). Sin embargo, en la región se localiza una de las Contrebias celtibéricas de las fuentes: Contrebia Leukade, ciudad arévaca, identificada por Blas 
Taracena en 1926, cuyo apogeo se fecha entre los siglos III-II a.C., cuando alcanza una extensión de 13,5 has., encerradas tras una gran fortifición (PEREZ ARRONDO y GALVE, 1983: 99). Este yacimiento fue objeto de excavaciones por su descubridor y, más recientemente, se han llevado a cabo sondeos por Hernández Vera, habiéndose hecho la sugerente propuesta de la creación de un Parque Arqueológico en el lugar (1992). Pero junto a los arévacos sabemos que en los valles del Cidacos y del Alhama estaban asentados pueblos vascones (FATAS, 1992: 225). Y por último, sabemos que esta región estuvo ocupada, en gran parte, por los berones, pueblo del que Estrabón dice que forma parte de la migración céltica, y cuyo centro principal fue Vareia, identificada con el topónimo Varea, en los alrededores de Logroño (FATAS, 1992: 229)

Tras este sucinto repaso, queda claro que la situación actual sobre la investigación prehistórica en La Rioja es el resultado de un enorme salto cuantitativo y cualitativo, que se ha dado en las dos últimas décadas básicamente. No obstante, se hacen también evidentes ciertas carencias, que ya se citaron con anterioridad, como las que se refieren al Epipaleolítico, al proceso de neolitización, o al Bronce Antiguo y Pleno. Lagunas que se van rellenando, poco a poco, con recientes aportaciones como las excavaciones de la Cueva Lóbrega en Torrecilla de Cameros (BARRIOS y CENICEROS, 1991), donde se documenta una secuencia estratigráfica ininterrumpida desde el Neolítico antiguo al Bronce final. Es de esperar que esta ampliación del horizonte de nuestros conocimientos de la Prehistoria riojana continue en los próximos años, gracias al trabajo de tantos y tantos profesionales comprometidos con la misma y a una correcta política de investigación arqueológica, por parte de los organismos oficiales interesados. 


\section{BIBLIOGRAFIA}

ARTEAGA, O. 1977

"Problemas de penetración céltica en el Pirineo occidental": XIV Congreso Nacional de Arqueología, Zaragoza.

BARRIOS, I y CENICEROS, J. 1991

"Excavaciones arqueológicas en Cueva Lóbrega (Torrecilla de Cameros)": Berceo 121.

BEGUIRISTAIN, M. 1982

Los yacimientos de habitación durante el neolítico y la Edad del bronce en el alto valle del Ebro, Pamplona.

BURILLO, F. 1992

"Etnias prerromanas en el valle del Ebro y Pirineos": Paleontología de la Península Ibérica, Complutum, 2-3, Madrid.

CASTIELLA, A. 1976

La Edad del Hierro en la Rioja y Navarra, Pamplona.

EIROA, J. 1978

"La cuenca del Ebro y sus territorios contiguos en la I Edad del Hierro": Cuadernos de Zaragoza, 25, Zaragoza.

ESPINOSA, U. 1984

Estudios de bibliografía arqueológica riojana: Prehistoria e Historia Antigua, Logroño.

FATAS,: G. 1992

"Para una etnogeografía de la cuenca media del Ebro": Paleoetnología de la Península Ibérica, Madrid.

GALVE, M $M^{\text {a }}$ P. 1978

Fuentes bibliográficas para la arqueología prerromana, Logroño.

GARCIA PRADO, J. 1983

Historia de La Rioja, Logroño.

HERNANDEZ VERA, J. A. 1982

Las ruinas de Inestrillas, Logroño.

MARCOS POUS, A. 1979

Trabajos arqueológicos en la Libia de los berones, Logroño.

MONTES, L. 1988

El Musteriense en la cuenca del Ebro, Zaragoza. 
PÉREZ ARRONDO, C. 1991

"El túmulo megalítico de La Hoyuela (Almarza de Cameros": Estrato, 2, Logroño.

PÉREZ ARRONDO, C. 1990

"El Megalitismo en la Rioja": Estrato, 3, Logroño.

RUIZ ZAPATERO, G. 1985

Los Campos de urnas del Noreste de la Península Ibérica, Madrid.

UTRILLA, P. 1990

Estado actual de la arqueología en Aragón: del Paleolítico al Neolítico: Estado actual de la Arqueología en Aragón, Vol. 1, Zaragoza.

UTRILLA, P. y PASCUAL, F. 1981

Yacimientos musterienses en terraza en el término de Calahorra (La Rioja), Calahorra.

UTRILLA, P. et alii 1986

El Paleolítico en la Rioja, Logroño.

VALLESPI, E. 1975

"Sobre las investigaciones prehistóricas en la provincia de Logroño": Caesaraugusta, 15-16, Zaragoza.

VALLESPI, E. 1960.

"Achelense final y Musteriense en el valle del Ebro": Homenaje al Prof. Beltrán, Zaragoza.

VV.AA. 1983

I Congreso de Historia de La Rioja, Logroño.

VV.AA. 1984

I Symposium de Historia de Calahorra. Bimilenario de su fundación, Calahorra.

VV.AA. 1985

XVII Congreso Nacional de Arqueología, Logroño, 1983, Zaragoza.

VV.AA. 1986

II Congreso de Historia de La Rioja, Logroño.

VV.AA. 1988

Celtíberos. Catálogo de la Exposición, Zaragoza. 